\title{
Outcome Assessment Of A Management Program Using A Portfolio Approach: Lessons Learned
}

\author{
Donald Drost, California State University San Bernardino, USA \\ Lee Hanson, California State University San Bernardino, USA \\ Clark Molstad, California State University San Bernardino, USA \\ Lloyd Peake, California State University San Bernardino, USA \\ Eric Newman, California State University San Bernardino, USA
}

\begin{abstract}
Over the past two decades the interest and use of student portfolios for assessing student learning outcomes has grown considerably. This paper presents an overview of the portfolio approach to outcome assessment adopted by the Department of Management at California State University, San Bernardino and discusses major issues encountered over six years of implementation. Experiences connected with the portfolio process are discussed from the perspectives of administrative complexity, the impact on academic program quality and evidence of assurance of student learning in relation to program learning objectives
\end{abstract}

Keywords: Outcomes, assessment, learning, portfolio, management, student, evaluation

\section{INTRODUCTION}

$\mathrm{n}$ response to accreditation requirements, mandates from governmental agencies or a genuine interest in continuous improvement of academic programs, outcome assessment plans have become commonplace (Banta, 2005). One outcome assessment method is the portfolio approach involving an evaluation of a collection of student works (Larson, 1991). Over the past two decades the interest and use of student portfolios for assessing student knowledge and skills in individual courses or academic programs has grown considerably (Banta, 2003; Johnston, 2004). Accordingly, considerable research has been conducted involving a myriad of issues ranging from the efficacy of portfolio assessment to critical program design and measurement issues (Banta, 2003). However, there are few published reports detailing experiences with using portfolios for outcome assessment. This article describes the experiences and implementation issues connected with a portfolio procedure used to assess student learning outcomes for the concentration in Management at California State University, San Bernardino. We begin by describing the design of the portfolio assessment process. We then discuss both faculty and student perceptions and issues concerning the portfolio requirement, and end with reflections about the usefulness of the portfolio process to all participants.

\section{MISSION, GOALS AND LEARNING OBJECTIVES}

One critical component of any outcome assessment process is to have "clear and explicitly stated purposes" (Banta, 1997, p. 83). Further, as White (2007, p.188) notes, "a well defined mission statement is the foundation for effective program assessment." Accordingly, in developing the outcome assessment procedure it was necessary to refine the mission of the Management department and then derive specific goals and learning objectives. The refined mission statement is as follows: 
To provide academically rigorous instruction in traditional, contemporary, and emerging management theory, research and practice and to stimulate student interest in management studies. The management faculty teaches students to understand the nature and needs of organizations, and to contribute both support and leadership in a variety of organizational roles. These roles include leadership in strategic and top management; and leadership at the department and functional levels, where skill in human relations, teamwork and interpersonal communications must be successfully applied by managers and other employees. The management faculty provides students with the knowledge and skills necessary to act as leaders at these various organizational levels and to serve as effective, ethical, contributing organization members.

From this mission the following learning goals were established:

1. To provide course experiences and assignments that will help develop students' proficiency in basic academic skills (writing, speaking, critical thinking) and help nurture advanced academic skills.

2. To provide an orientation to management which emphasizes international, cultural, ethical, legal, organizational-process, and economic perspectives?

3. To familiarize students with the role of uncertainty, limited information, risk and conflict in management decision making, so as to help them build tolerance for ambiguity and recognition that problems typically lack perfect solutions and requires prioritizing among options.

4. To provide opportunities for students to critically analyze and evaluate assumptions that they make about people and their behavior in organizations.

5. To offer relevant experience in team work and group-based learning and problem solving.

From these goals, twelve learning objectives subject to program assessment were developed. The twelve learning objectives are presented in Table 1 below.

Table 1: Learning Objectives

\section{Objective}

1. Demonstrate basic competency in written communications (defined as writing that is clear, concise, well organized and well reasoned).

2. Demonstrate basic competency in spoken communication.

3. Demonstrate critical thinking skills in case analysis and other written and oral communication exercises.

4. Demonstrate understanding of managerial issues and problems related to the global economy and international business

5. Demonstrate a basic grasp of how the legal system and regulatory system affect managerial decision-making

6. Demonstrate familiarity with social responsibility issues that managers must address, including but not limited to business ethics, corporate lobbying, cultural diversity, and environmental issues.

7. Demonstrate understanding of organizational conflict resolution, power and politics that influence managerial situations.

8. Demonstrate an understanding of both the strengths and weaknesses of managerial problem analysis, problem solving and decision-making techniques.

9. Demonstrate ability to critically analyze organizational problems involving people, situations, and behavior in light of established managerial theory and practice.

10. Demonstrate understanding of the complexities of various organizational role expectations including leader, manager, supervisor, subordinate and team member.

11. Demonstrate knowledge of the theory and practice of team-based organization and team management skills.

12. Demonstrate knowledge of the techniques of employee supervision and human resource management including leadership, motivation, productivity, job design and managing organizational change.

As Banta (1997, p. 82) notes: "Assessment is most effective when it reflects an understanding of learning as multidimensional, integrated, and revealed in performance over time." Thus, rather than relying upon exams and student grades alone, a portfolio system for outcome assessment was developed consisting of student papers and projects from each management concentration course. Students assemble these assignments into portfolios that are evaluated against program goals and learning objectives. 


\section{PORTFOLIO ASSIGNMENTS}

In each course in the Management concentration, faculty members are required to assign a project designed to assess at least four of the twelve learning objectives presented in Table 1. Because the portfolio assignments are the key to the success of the outcome assessment process, faculty members are encouraged to design assignments that provide students with an opportunity to demonstrate their most distinguished performance and scholarly accomplishments. Examples of appropriate portfolio assignments include a research paper or other written report, a case analysis, an essay, or other well developed written material. Faculty members are required to provide a standardized cover sheet for each portfolio assignment that explains the purpose(s) and the learning objectives assessed. Further, this cover sheet must include a Likert-type scale used for evaluating a student's level of attainment for each learning objective (see Figure 1). These scales serve as the basis for a summative assessment of student achievement on the learning objectives.

Using an examination for a portfolio assignment is not acceptable. A primary reason for adopting the portfolio process was a consensus among faculty members to steer away from student examinations as the exclusive means for course assessment. Furthermore, as Banta (1997, p. 83) suggests, "assessment requires attention to outcomes, but also and equally to the experiences that lead to those outcomes." As such, it was anticipated that requiring meaningful assignments and/or projects in each concentration course would add an element of rigor to the curriculum to enhance student learning.

Figure 1: Sample Portfolio Assignment Cover Sheet

Portfolio Assignment Cover Sheet

Management 355, Business and Society

\section{(Student Name)}

The assignment provided below is the portfolio assignment for the class. The assignment is intended to provide evidence of the following outcome assessment competencies:

1. Basic competency in written communication (defined as writing which is clear, concise, well-organized, and well reasoned).

2. Demonstrate familiarity with social responsibility issues that managers must address, including, but not limited to business ethics, corporate lobbying, cultural diversity, and environmental concerns.

3. Critical thinking skills in case analysis and other written and oral communication exercises.

4. An ability to critically analyze organizational problems involving people, situations, and behavior in light of established managerial theory and practice.

\section{The Portfolio Assignment}

Read the following cases... Then present a five page typewritten answer to the following question:

Considering the role of government policy in overseas bribery as discussed in the two cases, what would you do if you were an American manager overseas and were told by an international official that if you didn't pay a bribe, you would not get a contract that your firm wanted?

Level of student performance on each assignment objective:

$\begin{array}{llllllll}\text { Objective No. } 1 & \text { Low } & 1 & 2 & 3 & 4 & 5 & \text { High } \\ \text { Objective No. } 2 & \text { Low } & 1 & 2 & 3 & 4 & 5 & \text { High } \\ \text { Objective No. } 3 & \text { Low } & 1 & 2 & 3 & 4 & 5 & \text { High } \\ \text { Objective No. } 4 & \text { Low } & 1 & 2 & 3 & 4 & 5 & \text { High }\end{array}$




\section{STUDENT SELF-EVALUATION ESSAY}

As will be described in the "assessment" section below, tabulating data from the scales on the portfolio assignment cover sheets provides summative assessment measures for the learning objectives. However, the assessment scales alone do not provide for any type of formative assessment of student perceptions of learning that occurred via the portfolio assignments. To address this issue, each student is required to write and include in his/her portfolio a self-evaluation essay that addresses the following questions:

- What aspects of the management program did you find most interesting? Least interesting?

- Has the management program help you change or develop your career goals? In what ways?

- What has the management program helped you learn about your own skills and abilities? What skills and abilities have you developed? What skills and abilities do you still need to learn and develop?

- $\quad$ Are there changes in the management curriculum that you would recommend that you believe would enhance our program?

- What have you learned about doing these portfolio assignments?

The self-evaluation essay is viewed as a critical component of the outcome assessment process for a number of reasons. First, it provides feedback from students regarding skills and competencies that they have developed through their programs of study. Second, understanding that learning should not end with a program of study, it requires student reflection upon what skills and abilities still need to be developed. Third, it requires students to integrate and reflect what they learned and accomplished over their entire program of study and how that knowledge influences their career aspirations. Finally, there were questions about how receptive students would be to a portfolio requirement given that other departments within the College of Business and Public Administration were using other approaches for outcome assessment. A concern was that students might switch concentrations to avoid having to meet the portfolio requirement. The self-evaluation provides a mechanism to assess student sentiment regarding the value of the assignments and the perceived value of the portfolio process.

\section{THE STUDENT PORTFOLIO}

At the conclusion of their program of study, students are required to submit for review a portfolio of works that consists of the following materials:

- A typewritten index that includes a brief description of each assignment and the course number, title and instructor for which it was completed.

- $\quad$ Five portfolio assignments from among five of the concentration courses completed. The portfolio assignment cover sheet must accompany each item.

- $\quad$ A portfolio self-evaluation essay.

To ensure submission of a portfolio, each student is required to enroll in and receive "credit" for the portfolio assessment course. The course is a zero unit, credit/no credit course (zero units so students do not have to incur additional tuition expense). However, credit in the course is a graduation requirement, which serves to impel each student to submit a portfolio containing the items noted above. Also, though students are required to complete six courses in the management concentration, only five assignments are required to accommodate situations where an assignment might be misplaced or was not returned by the instructor.

\section{PORTFOLIO ASSESSMENT}

A summative assessment of student achievement with respect to the learning outcomes is conducted by tabulating the information contained on the portfolio cover sheets that accompany each student assignment. Approximately thirty to fifty portfolios are submitted each quarter, so it requires tabulating data from approximately 150 to 250 student projects. Data are recorded for each quarter and are later accumulated for an entire academic year. Results of an assessment for a prior academic quarter are contained in Figure 2. 
Figure 2

Summary of Scores on Learning Objectives

\section{Learning Objective}

1. Demonstrate basic competency in written communication (defined as writing that is clear, concise, well organized and well reasoned).

2. Demonstrate basic competency in spoken communication

3. Demonstrate critical thinking skills in case analysis and other written and oral communication exercises.

4. Demonstrate understanding of managerial issues and problems related to the global economy and international business

5. Demonstrate a basic grasp of how the legal system and regulatory system affect managerial decision making.

6. Demonstrate familiarity with social responsibility issues that managers must address, including but not limited to business ethics, corporate lobbying, cultural diversity, and environmental issues.

7. Demonstrate understanding of organizational conflict resolution, power and politics that influence managerial situations.

8. Demonstrate an understanding of both the strengths and weaknesses of managerial problem analysis, problem solving and decision-making techniques.

9. Demonstrate ability to critically analyze organizational problems involving people, situations, and behavior in light of established managerial theory and practice.

10. Demonstrate understanding of the complexities of various organizational role expectations including leader, manager, supervisor, subordinate and team member.

11. Demonstrate knowledge of the theory and practice of team-based organization and team management skills.

12. Demonstrate knowledge of the techniques of employee supervision and human resource management including leadership, motivation, productivity, job design and managing organizational change.

\begin{tabular}{|c|c|c|c|c|}
\hline Low & & & & High \\
\hline 1 & 2 & 3 & 4 & 5 \\
\hline 0 & 5 & 10 & 29 & 64 \\
\hline 0 & 0 & 1 & 6 & 7 \\
\hline 0 & 3 & 14 & 25 & 56 \\
\hline 0 & 0 & 10 & 3 & 8 \\
\hline 0 & 0 & 6 & 8 & 12 \\
\hline 0 & 0 & 0 & 7 & 21 \\
\hline 0 & 0 & 1 & 4 & 2 \\
\hline 0 & 2 & 6 & 8 & 22 \\
\hline 0 & 2 & 16 & 17 & 38 \\
\hline 0 & 0 & 0 & 1 & 2 \\
\hline 0 & 0 & 4 & 8 & 9 \\
\hline 0 & 0 & 7 & 6 & 12 \\
\hline
\end{tabular}

This assessment provides measurement of how faculty members perceive students met the learning objectives designated for the portfolio assignments. Over six years of evaluation, the results obtained and presented above have remained fairly consistent from quarter to quarter. As typified by the data above, faculty members believed that students demonstrate basic competency on most of the learning objectives, particularly with respect to written communication skills and critical thinking skills. Conclusions concerning other learning objectives, most notable, basic competency in spoken communication, an understanding of organizational conflict resolution, power and politics, and the complexity of various role expectations including leader, manager, supervisor, subordinate and team member, have been more difficult to make since the number of assignments assessing them have been few and relatively sporadic. As a result, faculty members have been encouraged to develop portfolio assignments that address a wider variety of learning objectives. Nonetheless, over several years of implementation, reasonable data have been accumulated for most learning objectives.

The student self-evaluation essays are reviewed and salient issues addressed under each question are recorded and summarized in a report format. As expected, a wide variety of viewpoints and issues have been 
expressed. Much has been learned about course material overlap, perceived value of course content, course scheduling, etc. The results have provided useful information regarding each of the questions asked. For example, with respect to the question: "What has the Management program helped you learn about your own skills and abilities," typical comments include:

How to work effectively in groups and recognizing working in groups is priceless when it comes to generating ideas.

To think analytically, problem identification, and learning how to resolve problems.

How to write papers and how to present them.

If I had to list everything I learned during my studies at CSUSB, I would be writing for the next sixteen months.

Many students have been equally reflective in addressing the question regarding skills and abilities that still need to be learned and developed. Students typically express a need to refine their written and oral communication skills, avoid procrastination, to speak up more often and/or be more assertive in group settings, etc. Most noteworthy is the widespread enthusiasm regarding the portfolio assignments and the portfolio process. Sample comments include:

I feel a sense of pride that I have produced these projects and many other works not included in the portfolio.

These portfolio assignments taught me to be disciplined, focused and creative.

Skills that have been developed through the process of completing portfolio assignments will carry over into my career and assist me in many ways --- every student in every major should have to produce a portfolio.

While not all comments are as enthusiastic, collectively, there is little question that students perceive that the portfolio requirement has had a positive influence on learning. Only about one out of every fifty self-evaluation essays reflects negatively on the portfolio process. The number of critical comments clearly has been far fewer than anticipated. Of course, since most students submit their portfolios the week prior to their graduation, there could be an inclination toward risk avoidance and a disposition toward providing a more positive slant. However, general lack of expressions of student discontent, either in essays or elsewhere, suggests that the portfolio requirement is accepted and valued by students.

\section{LESSONS LEARNED}

After six years of implementation, the experiences using a portfolio approach for outcome assessment have been mixed. The basis for this conclusion will be explained from three perspectives; administration (administrative complexity and cost), academic quality (impact on the quality of education) and outcome assessment (evidence of student achievement with regard to learning objectives and programmatic assessment).

\section{ADMINISTRATION}

From an administrative perspective, the portfolio process is somewhat cumbersome. At the beginning of the process, enrolling students into the portfolio course requires staff support. To ensure that only students submitting a portfolio enroll in the course, students have to obtain permission to enroll from the department office. It only took one quarter to realize that if enrollment was not restricted, students from various other majors and/or concentrations would enroll in the course. This resulted in a grade roster including dozens of students not subject to the portfolio requirement and these students had to be dropped after the quarter, which is administratively complex. Also, every student must submit his or her portfolio to the department office in order to obtain a receipt as proof of submission in the event a portfolio is misplaced. Even with this requirement, cases arise when students receive "no credit" for alleged failure to submit a portfolio. Yet in a number of cases, students claim they submitted a portfolio and received no receipt. Since this is generally the only requirement standing between and student and receipt of his 
or her diploma, the situation can be problematic. To resolve these cases, students are required to assemble a portfolio with copies of their assignments and submit a new self-evaluation essay.

Awarding either a credit, no credit or incomplete to students enrolled in the portfolio assessment course is generally straightforward. If a student portfolio contains the required materials, credit is awarded. However, problems are encountered when materials are missing. Most problematic are portfolios containing fewer than five assignments due to a myriad of reasons (e.g., transfer students that received credit for concentration courses taken at other institutions, instructors not returning assignments or returning them after the due date for the portfolio, etc.). This often results in having to award an "incomplete" and file associated paperwork. Although a student instruction guide is widely disseminated explaining how to address these issues, and students are regularly briefed in the department office, the portfolio requirement remains an administrative headache.

The issue of storage of portfolios has been identified in the literature as a potential challenge (Banta, 2003), however this has proven to be more a nuisance than a serious complication. To restrict storage requirements to a couple of file cabinets, portfolios are discarded after one year. Students are advised of this via an instruction guide and are allowed to submit photocopies of their work (emphasizing that the portfolio cover sheets and instructor comments must accompany all copies).

The most complex and time-consuming task involves portfolio assessment. Each quarter approximately 30 to 50 portfolios are submitted. Recording and tabulating the data from 150 to 250 portfolio assignments takes a considerable amount of time. However, it is the content analysis of the self-evaluation essays that is most time consuming. Recording the salient information and writing a summary report each quarter requires substantial effort.

In summary, though the experiences highlighted are manageable, they suggest that the portfolio is not one of the more administratively "efficient" means for conducting outcome assessment.

\section{ACADEMIC QUALITY}

From an academic quality perspective, adopting the portfolio requirement has produced numerous benefits. First, both faculty and students have expressed belief that requiring a portfolio assignment in each concentration course has improved the academic quality of the courses. Numerous students reflected in their self-evaluation essays that the assignments provided a far better venue for applying course materials than exams (particularly multiple choice exams). Though many faculty members already required a project prior to the adoption of the portfolio requirement, some did not. Thus, the portfolio process has established a standard for both tenure-track and adjunct faculty members that has enhanced academic quality. Second, the self-evaluation essays have clearly helped students integrate and reflect upon their programs of study and gain a fuller understanding of skills and abilities they have acquired and the skills and abilities they still need to develop. To this end, it appears that the process has led to what White (2003. p.39) refers to as "metacognition --- helping students to acquire an understanding of what they know and what they do not yet know about the process of learning." Third, as noted earlier, students have responded very favorably to the portfolio requirement. The vast majority of students have indicated that completing the assignments and the self-evaluation essays were genuine learning experiences.

\section{OUTCOME ASSESSMENT}

From an outcome assessment perspective the results have been mixed. On the positive side, the student self-evaluation essays have provided information that has led to program improvement. Notable has been information related to courses that students found most useful/least useful which has resulted in one course previously required to now be offered as an elective. Information regarding extensive overlap of materials across courses, has also led to discussion and change regarding course content. The summative assessment of the learning objectives suggests that there are some that have not been addressed sufficiently via portfolio assignments. Though this does not necessarily mean that the learning objectives have not been addressed in courses, it does imply that some are not being evaluated to the degree desired. The result has been to encourage faculty members to develop assignments that address a wider range of learning objectives. Finally, student comments about the value of 
internships have led to greater departmental (as well as College) efforts in establishing more internship opportunities.

The summative assessments of student achievement regarding the twelve learning objectives have proven to be less useful than the student reflection essays from the perspective of program improvement. This is because the Likert Scale data reflect that faculty members believe that the vast majority of students have demonstrated the competencies and/or skills related to most learning objectives. For example, approximately $80 \%$ of students received either a 4 or 5 on the majority of learning objectives. Given that students submit what Katz and Gangnon (2000, p. 7) refer to as a "showcase portfolio" consisting of students' better works, the positive results are not surprising. Not only are students permitted to submit five of their best portfolio assignments, faculty have been encouraged to have students rework and polish portfolio assignments to improve the quality of the end-product. However, because the data indicates that students are mastering the competencies and skills evaluated, there is little data suggesting that curriculum changes are warranted in the spirit of continuous improvement. This is a crucial issue, for as Martell (2007, p. 192) so aptly notes, “... the whole purpose of collecting and assessing program learning goals is to use this data to improve the curriculum." This is not to suggest these data are not useful, just not to the extent anticipated. Moreover, the summative assessment of student achievement regarding the learning objectives has exposed a paradox. As noted above, approximately $80 \%$ of students are awarded either a 4 or 5 on the majority of learning objectives. However, contrary to the statistical findings are frequent faculty member comments suggesting that many students possess marginal written communication and critical thinking skills. Though faculty commentary does not provide a systematic means for which to assess student achievement, it has tended to run counter to the summative assessment of student achievement on the learning objectives. It could be that faculty merely remember the negative cases far more vividly than the positive. On the other hand, it may well derive from problems with the reliability and validity of the faculty evaluation data, which is common to the assessment of works contained in student portfolios (Johnston, 2004). As a result, discussion has ensued surrounding the feasibility of conducting a second review of student portfolio assignments in order to assess the validity of the scores assigned to the learning objectives. While this would clearly be useful for alleviating concerns regarding the accuracy of assessment, it would add another level of review to an already resource-heavy process. However, sampling could somewhat reduce the workload associated with the additional assessment.

\section{SUMMARY}

What has been learned about this portfolio approach to outcome assessment after six years of implementation? First, the process is administratively complex and time consuming. Though the student instruction guidelines have been refined to address chronic administrative problems, numerous administrative difficulties persist. This problem has led to discussion within the department whether or not consideration should be given to adopting other approaches to outcome assessment that could potentially achieve the same results in a more expedient manner. Second, it is clear that the portfolio requirement and accompanying course assignments have raised the academic quality of the Management program. Students have consistently related that completing the portfolio assignments, writing their self-evaluation essays and reflecting on their programs of study have been genuine learning experiences. Also, requiring all instructors of Management concentration courses to assign a meaningful project in each concentration course has helped improve the rigor of the curriculum. Third, the summative assessments have yielded evidence with respect to the degree that students are achieving the learning objectives. Though some question remains regarding the validity of the results, the design of the portfolio process was not intended to offer absolute proof regarding student proficiency on the learning objectives, just credible evidence. Fourth, the formative assessments via the student self-evaluation essays have provided information regarding a number of critical programmatic issues, including perceived course utility, curriculum overlaps, course scheduling problems, etc. Finally, students have been very receptive to the portfolio requirement. While there was initial concern that students would merely view this requirement as just another hurdle to jump in their quest to obtain their college degrees, such has not been the case. Student comments overwhelmingly reflect pride with their work and their portfolios. The positive student perceptions regarding the portfolio requirement has clearly led to a higher degree of satisfaction with their management education experiences. 


\section{AUTHOR INFORMATION}

Donald Drost, Ph.D is a Professor of Management at California State University, San Bernardino, where he teaches human resource management courses. He received his Ph.D. in Management from Virginia Polytechnic Institute and State University. Dr. Drost has authored or co-authored numerous articles on HR-related topics and has consulted with numerous organizations regarding a variety of human resource management issues.

Lloyd Peake earned his J.D. from Southwestern University School of Law and has taught at CSUSB for over 20 years primarily in the areas of Legal Environment of Business and Fair Employment Practices. He was Chair of the Management Department's Outcomes Assessment Committee from 1998 - 2005.

Clark Molstad earned his Ph.D. at UCLA and has taught at Cal State, San Bernardino for 25 years. He teaches OB, OT, and Industrial Relations. He has been involved in outcome assessment and student portfolios for ten years.

Lee Hanson earned his Ph.D. in Administration from the University of California, Irvine. His field is strategic management. He has been involved outcome assessment since it was first established in the College of Business and Public Administration.

Eric Newman, Ph.D. is a Marketing Professor at Cal State San Bernardino, where he specializes in Experiential Marketing. He has a Ph.D. from Washington State University and an MBA from the University of Montana. Dr. Newman is also involved with Native American educational outcomes and assessment.

\section{REFERENCES}

1. Banta, Trudy W. (1997). Moving Assessment Forward: Enabling Conditions and Stumbling Blocks. In New Directions for Higher Education, No. 100. San Francisco: Jossey-Bass.

2. Banta, Trudy W. (2003). Introduction: Why Portfolios? In T.W. Banta (Ed.), Portfolio Assessment: Uses, Cases, Scoring and Impact. San Francisco: Jossey-Bass, 1-5.

3. Banta, Trudy W. (2005). How Much Have We Learned? BizEd, 4, 35-38.

4. Johnston, Brenda, (2004). Summative Assessment of Portfolios: An Examination of Different Approaches to Agreement over Outcomes. Studies in Higher Education, 29, 395-412.

5. Katz, Albert M. and Gangnon, Bradley A (2000). Portfolio Assessment: Integrating Goals and Objectives with Learner Outcomes. Assessment Update, 12, No.1, 6-13.

6. Larson, Richard L. (1991). Using Portfolios to Assess the Impact of a Curriculum. In T.W. Banta (Ed.), Portfolio Assessment: Uses, Cases, Scoring and Impact. San Francisco: Jossey-Bass, 7-10.

7. Martell, Kathryn (2007). Assessing Student Learning: Are Business Schools Making the Grade? Journal of Education for Business, 82, 189-195.

8. White, Bonnie J. (2007). Perspectives on Program Assessment: An Introduction. Journal of Education for Business, 82, 187-188.

9. White, Carmel Parker (2004). Student Portfolios: An Alternative Way of Encouraging and Evaluating Student Learning," in New Directions for Teaching and Learning, No. 100, (Winter 2004), Wiley Periodicals, Inc.: 37-42. 
NOTES 